\title{
Enhanced Skill of Tourism Communication: Development of Model Question Levels During Tour Sessions
}

\author{
Roswati Abdul Rashid ${ }^{1, *}$, Zanjabila Nudin ${ }^{1}$, Ahmad Shamil Kamaruzaman ${ }^{1}$, \\ Mazlina Ahmad ${ }^{1}$, Nurul Ain Chua Abdullah ${ }^{1}$ and Roslina Mamat ${ }^{2}$ \\ ${ }^{1}$ Center of Foundation and Continuing Education, Universiti Malaysia Terengganu(UMT), Malaysia \\ ${ }^{2}$ Faculty of Modern Languages and Communications, Universiti Putra Malaysia (UPM), Malaysia \\ *Corresponding author. Email: roswati@umt.edu.my
}

\begin{abstract}
Questioning is an activity that takes place in our daily lives. It has been said that one's knowledge is gained by questioning. Tourism communication which is involved intercultural elements may still need be consciously careful of socially and culturally of other cultures' norms when questioning. Therefore, this study was aimed to explore how the questioning were applied or formed by Japanese-speaking Malaysian to Japanese tourists during tour trip session. Based on attributes and categories of questioning, this study will developed a model of question levels that were often used throughout the visit. This study is a qualitative study and the data is collected through audio, visual and observational notes on the interaction of five Malay tour guides when using the Japanese language while interacting with 17 Japanese tourists during four sets of Free Independence Travel (FIT) package. The findings showed that for the purpose of smooth communication, various categories of questions were applied due to the application of coordination and adjustment. The findings also revealed that the level of questions applied during the tour session were only at Level 1 of both domains of the Taxonomy of Educational Objectives, Bloom (1984) [1]. This study is expected to become a reference point in the field of education and the domain of learning the Japanese language. Owning in the application of questions can be enhanced with the use of suitable applied questions while explaining the tourism destination. This study is most relevant to the key players in the national tourism industry, most specifically tour guides.
\end{abstract}

Keywords: level of question, tour guide, Japanese tourist, Malaysian tourism, tourism communication

\section{INTRODUCTION}

In learning process, questioning plays an important role. In fact, questioning has been identified as a strategy that is able to influence learning and also one of the strategies to deliver learning content which can improve the level of a student's achievement. The use of question-based strategies in teaching and learning (T\&L) which are aimed to increase anticipation, stimulate curiosity, seek different views and act as a provocative element to stimulate new ideas. As Aydemir and Çiftçi (2008) [2] summarized that questions are stimulants which activate students' cognitive skills and they have functioned as a primary educational tool for centuries.
However, questioning need not only be focused on the context of learning but can also play an important role in other social communication domains. Some individuals in social societies have the power and the right to ask questions/practise questioning and obtain answers such as doctors, policemen, teachers, lawyers, etc., according to the context of their respective scope of power and authority.

"Questions can determine how a conversation proceeds; they can determine the next speaker; attract and show attention; exhibit confidence or insecurity and they can focus the listener's thought. If successful in receiving information, or an understanding from having asked a question, then the learner has then 
shown competence in his or her ability to make the request, and communication has occurred."

Tyers (2000: 163)[3]

This is no exception for tour guides (TGs), in their task of conducting a guided tour trip session (GTTS), who use their authority and rights to ask questions/practise questioning to enable smooth communication with their tourist groups. Therefore, the objective of this study is to summarise the application of the questioning strategies that are required for smoothness and continuity during the GTTS process. Although for the time being, due to the Coronavirus pandemic, all physical tourism activities especially for tourist visits are prohibited but this research is still relevant in the context of tourism communication. Questioning is expected to be more crucial at this time because for those who want to travel inbound or outbound travel need to update themselves on the actual situation in order to do tourism activities. Therefore it is important that the features of questioning, including the level of questions and the categories of questions asked by the TGs, are based on the context of tourism so that the application of the questions are most effective in smoothing the GTTS process.

\section{PROBLEM STATEMENT}

The functions of inquiry in learning and teaching are to initiate discussions, review material, as a guide to problem solving, diagnose student abilities, assess student readiness, control behavior, stimulate creative or critical thinking and encourage contributions. Apart from that, questions also aim to clarify misunderstandings, support conceptual development, strengthen understanding and ask students to explain in more detail (Zamri Mahamod \& Nor Razah Lim, 2011)[4]-[7] . But their study only examined the function and characteristics of inquiries among respondents from the same cultural background. Asking questions requires the selection of the appropriate grammar structure and context of its use. In addition, the GTTS context requires coordination and adaptation by TG to the target tourist culture. The culture underlying a community is different from one community to another. Therefore, of course, patterns, styles, rules, characteristics, etc. in raising questions between one culture and another culture are different because they are influenced by the underlying culture [8].

Therefore, does TG Malaysia BJ ask the appropriate questions as outlined in the Japanese tourist community and whether Japanese tourists will respond as usual to give feedback when asked questions. It is a necessity to know the cultural patterns of the target language which is the main basis for the study of query strategies in this study. Without that knowledge someone who is not a native speaker will give the wrong impression about themselves and will invite misunderstanding. The need for mastery of these language skills is further strengthened by the argument of Devereux (1998)[9]. According to him, the application of foreign language knowledge and skills in communication in the tourism industry is part of the efficiency of cross-cultural services in the quality tourism industry.

\section{QUESTIONING IN T\&L}

To date, most surveys of the application of questioning strategies have been focused in the context of T\&L and these strategies have been recognised as one of the most effective methods of channelling knowledge.

In addition, applying these strategies has also been identified as a mode to achieve a more dynamic learning outcome. For example, students may be given the opportunity to relate various learning content, and the ability to improve their understanding of how they can channel their learning outcomes that are understood in a cross-section [10].

According to Cecil and Pfeifer (2011)[11], questioning was claimed to be a direct method which was effective and able to increase the understanding of reading in students, especially when the teacher asked good questions and taught the students how they should apply their own questions. Finally, the application of a strategy of questioning was able to develop the students' imagination, especially, when they were given the opportunity to give ideas, finding connections and the most importantly when returning questions back to the teacher.

Overall, all of the outcomes or results of applying the strategy of questioning in a $T \& \mathrm{~L}$ guides and refines the students towards a higher-level thinking, or in other words, it increases the cognitive power of students during the learning process. From the point of view of the purpose of questioning, Cecil and Pfeifer (2011) [11] listed the four most important categories for the purpose of questioning in T\&L, as shown in Figure 1. According to them, a teacher may use questions for various purposes. Usually, the purpose of the questions is derived simultaneously.

For example, a teacher may ask questions to test the level of understanding of certain topic concepts during teaching whilst at the same time asking the impartiality of the aforementioned concept during teaching in order to encourage the students to make decisions or to solve problems. Alternatively, the teacher may ask questions to gauge the behaviour/response of the students or to obtain the student's opinions about the concept of the topic.

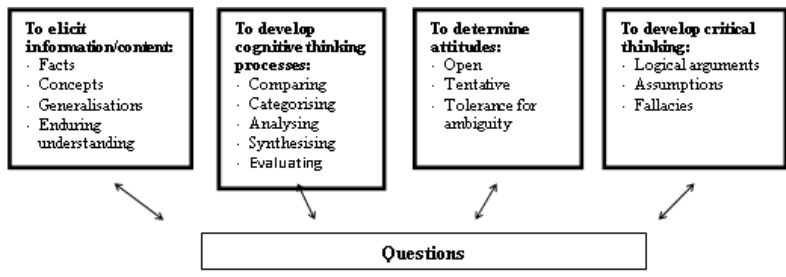

Figure 1 Multiple purposes of questions (Cecil \& Pfeifer, 2011)[11]

Meanwhile, Noraini Idris (2001) [6] developed a model for the role of questioning in the T\&L contexct - Figure 2 . 
According to her, questioning activity provides the basis for implementing other teaching skills and emphasises that a teacher should take into account some of the ongoing processes whilst questions are being asked. Among the processes that should be considered are; to identify the purpose of teaching, controlling communication while delivering lessons, measuring verbal and non-verbal responses/feedback by the students, administering students' behaviour and thinking of further questions to be asked.

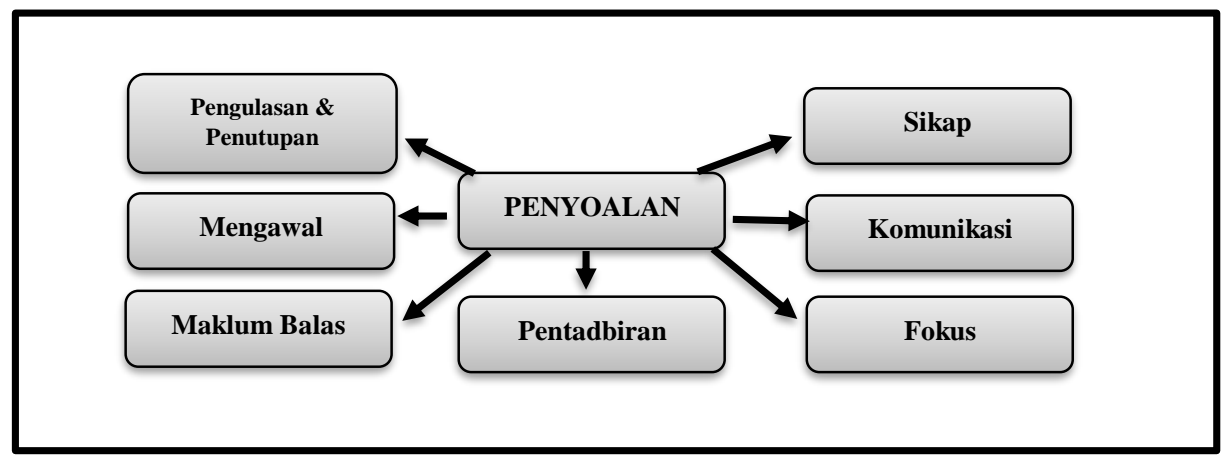

Figure 2 The Role of Questioning in Teaching (Noraini Idris, 2001) [6]

Noraini Idris (2001) [6] summarized, questioning becomes an important teaching method for teachers. The teacher serves as a coach to help students to understand the learning process, and via this method, the teacher is able to receive direct feedback from students. Therefore, questioning provides an opportunity for teachers to obtain more diverse information from students than teaching without questioning would be able to achieve. Whereas, Cunningham (1987) [5] 's model - Figure 3 for the level of questions in teaching stated that in teaching there are two domains which are cognitive and affective domains support each other to enable students to better understand the learning process and allows the learning process to become fun. According to Cunningham (1987) [5], these two domains support each other which makes students will better understand learning and even make learning fun.

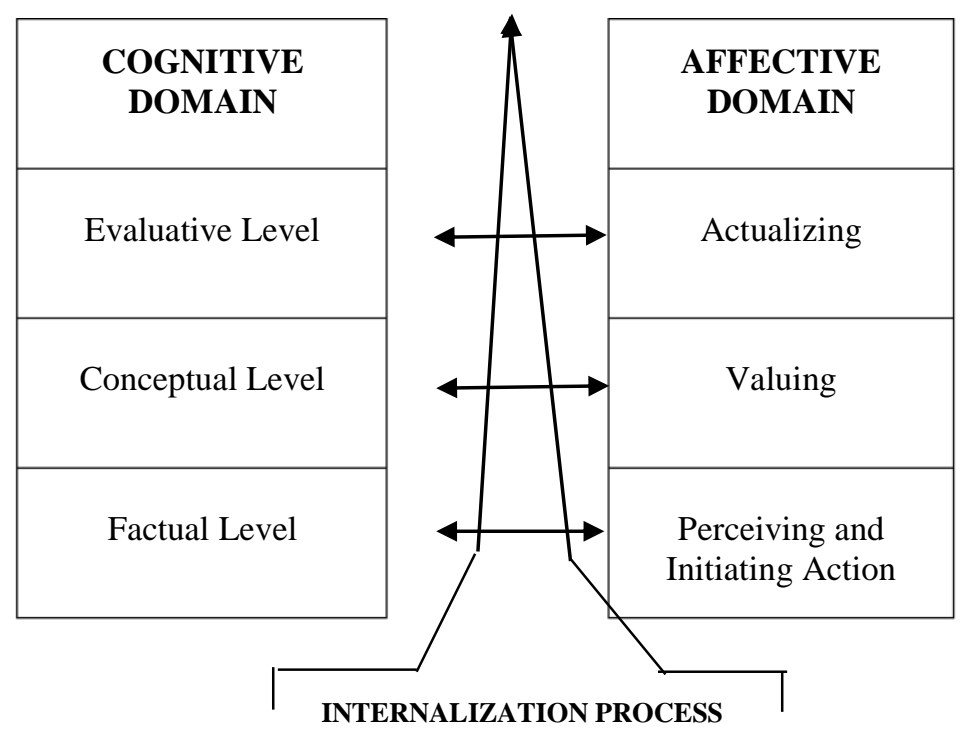

Figure 3 Model for Kinds of Cogntive and Affective Questions

There have been many more question models developed in the context of T\&L. These have aimed to develop quality questions in order to boost the intellectual thinking and also to stimulate the response of thoughts by the students. In fact, these models have become guidelines or conceptual frameworks for educators in formulating effective questions, and especially, to guide students in their thinking [12]. 


\section{MODEL OF QUESTION LEVEL TAXONOMY OF EDUCATIONAL OBJECTIVES (TOEO) -BLOOM (1984) [1]}

There are a variety of levels of question taxonomy that have been developed in order to form quality questions to assist educators. Among them are Bloom (1956) [13], Sanders (1966) [14], Cunningham (1987) [5], Noor Rohana Mansor (2007) [12], Cecil and Pfeifer (2011) [11] and Muthy (2013) [15]. However, this research has only discussed the Taxonomy of Educational Objectives (TOEO), Bloom (1984) [1] which has also been referenced by most other studies. Specifically Bloom explained the level of questions in the context of T\&L in classrooms which has become the best model to follow [16].

This taxonomy has been utilised in the field of education in particular, and its use has been expanded until the current time in various aspects related to educational skills. Tables 1 and 2 below detail the TOEO as described by Cecil and Pfeifer (2011) [11]. Table 1 shows six categories that divided three levels according to the hierarchy of cognitive thinking processes.

Table 1 Bloom's Cognitive Domain - Categories of Question (Cecil \& Pfeifer, 2011) [11]

\begin{tabular}{|c|c|c|c|}
\hline Level & Question Type & Response Behaviours & Eliciting Question Starts \\
\hline \multirow[t]{8}{*}{ I } & Knowledge & Recalling facts or observations. & 1. Who...? \\
\hline & & Recalling definitions. & 2. What...? \\
\hline & & & 3. Where...? \\
\hline & & & 4. When...? \\
\hline & & & 5. Define (the word prosper). \\
\hline & Comprehension & Giving descriptions. & $\begin{array}{l}\text { 1. Describe (what happened when the third } \\
\text { goat went over the bridge). }\end{array}$ \\
\hline & & & 2. What is the main idea (in this paragraph)? \\
\hline & & & 3. How are (two fruits alike)? \\
\hline \multirow[t]{7}{*}{ II } & Application & Applying techniques & 1. Why (did Old Yeller die)? \\
\hline & & & 2. What (is the perimeter of your living room)? \\
\hline & Analysis & Identifying motives or causes. & 1. Can you think of (a way to test this)? \\
\hline & & Making inferences. & 2. How can we solve (this problem)? \\
\hline & & Finding evidence & 3. How can we improve (our research)? \\
\hline & & generalisations. & $\begin{array}{l}\text { 4. What will happen (now that we have found a } \\
\text { cure for cancer)? }\end{array}$ \\
\hline & & & $\begin{array}{l}\text { 5. What do you predict would happen (if we all } \\
\text { looked the same)? }\end{array}$ \\
\hline \multirow[t]{11}{*}{ III } & Synthesis & Solving problems. & 1. Can you think of (a way to test this)? \\
\hline & & Making inferences. & 2. How can we solve (this problem)? \\
\hline & & Finding evidence & 3. How can we improve (our research)? \\
\hline & & generalisations. & $\begin{array}{l}\text { 4. What will happen (now that we have found a } \\
\text { cure for cancer)? }\end{array}$ \\
\hline & & & $\begin{array}{l}\text { 5. What do you predict would happen (if we } \\
\text { all looked the same)? }\end{array}$ \\
\hline & Evaluation & Giving opinions about issues. & 1. Do you agree (with Jose)? \\
\hline & & $\begin{array}{l}\text { Judging the validity of ideas. } \\
\text { Judging the merit of problem }\end{array}$ & $\begin{array}{l}\text { 2. Do you believe (that this is the best way to } \\
\text { proceed)? Why? }\end{array}$ \\
\hline & & $\begin{array}{l}\text { solutions. } \\
\text { Judging the quality of art and other }\end{array}$ & $\begin{array}{l}\text { 3. Do you think (that it is right to judge } \\
\text { criminals)? Why? }\end{array}$ \\
\hline & & $\begin{array}{l}\text { products. } \\
\text { Judging opinions and ideas. }\end{array}$ & $\begin{array}{l}\text { 4. What is your opinion (on this matter)? } \\
\text { Why? }\end{array}$ \\
\hline & & & 5. Would it be better (to do it this way)? Why? \\
\hline & & & 6. Which (video) did you like/ Why? \\
\hline
\end{tabular}

Furthermore, according to Cecil and Pfeifer (2011) [11], the application of questioning strategies during a $T \& L$ session must not only focus on the cognitive domain category of questions as the affective domain category of questions also needs to be addressed. In reality, the cognitive and affective domains cannot be separated at all levels for students to process information without emotional feedback. The two domains tend to merge and move simultaneously. However, at times, a question is only relevant to one domain rather than to the other domain.

While the affective domain questions are applied when involving feelings and emotions, examples of behaviour, values, beliefs and impacts due to related feelings. Table 2 is similarly to the cognitive domain categories of questions, the affective domain is divided into three levels 
that are also classified according to the required stages of the process.

In the TOEO listed the processes of thinking that suited various areas [11]. The classifications based on this taxonomy are a concrete foundation to boost the skills and to stimulate student's thinking towards situations that require thought. Building a ground-based question from the lowest and simplest level to higher levels provides difficulties and challenges for the students. In fact, each and every level of question demonstrates a continuity of cognitive development to master specific skills bringing about real behavioural change.

Table 2 Bloom's Affective Domain - Categories of Question (Cecil \& Pfeifer, 2011) [11]

\begin{tabular}{|c|c|c|c|}
\hline Level & Question Type & Response Behaviours & Eliciting Question Starts \\
\hline I & $\begin{array}{l}\text { Receiving } \\
\text { (attending) }\end{array}$ & $\begin{array}{l}\text { Awareness of the } \\
\text { environment. } \\
\text { Willingness to receive. }\end{array}$ & $\begin{array}{l}\text { 1. Which would you prefer...? } \\
\text { 2. Identify the person who... } \\
\text { 3. Listen to this song by... } \\
\text { 4. Are you aware that... }\end{array}$ \\
\hline & Responding & $\begin{array}{l}\text { Acquiescence in responding. } \\
\text { Willingness to respond. } \\
\text { Satisfaction in response. }\end{array}$ & $\begin{array}{l}\text { 1. Do you like to sing? } \\
\text { 2. Did you observe the difference between the two } \\
\text { pieces? } \\
\text { 3. Are you willing to go to the ballet? }\end{array}$ \\
\hline II & Valuing & $\begin{array}{l}\text { Acceptance of a value. } \\
\text { Preference for a value, } \\
\text { Commitment. }\end{array}$ & $\begin{array}{l}\text { 1. Defend your stance (on gun control). } \\
\text { 2. Did you feel (responsible for the homeless)? } \\
\text { 3. Rank order your preferences... } \\
\text { 4. Do you agree or disagree that...? }\end{array}$ \\
\hline III & Organisation & $\begin{array}{l}\text { Conceptualisation of a value. } \\
\text { Organisation of a value } \\
\text { system. }\end{array}$ & $\begin{array}{l}\text { 1. In your opinion (is this money well spent)? } \\
\text { 2. As you view (the war, should we have entered } \\
\text { the conflict)? } \\
\text { 3. In your own words, explain the issue? } \\
\text { 4. Have you weighed the alternatives (for not } \\
\text { using animal research)? }\end{array}$ \\
\hline & Characterisation & $\begin{array}{l}\text { Generalised set. } \\
\text { A philosophy of life. } \\
\text { Values are internalised. }\end{array}$ & $\begin{array}{l}\text { 1. What will you do (about pollution)? } \\
\text { 2. Are you willing to (give up lunch one day a } \\
\text { week for the homeless)? } \\
\text { 3. What is your philosophy (on mercy killings)? } \\
\text { 4. Which of the following beliefs would you say is } \\
\text { the most important in your life? }\end{array}$ \\
\hline
\end{tabular}

\section{QUESTIONING DURING GUIDED TOUR TRIP SESSIONS (GTTS) DISCOURSE}

Similarly, to the education, communication during a GTTS also incorporates learning which requires the understanding of information about the relevant tourist destinations and the TG acts as an instructor.

If there are no questions during a tour then the GTTS will become arid, according to the argument made by Krismanto (2003) [4] and the smoothness of the GTTS will be affected. However, since learning during a GTTS is not a measurement-oriented exercise involving examinations, with tests etc. at the end of the session, thus the main aim of learning during a GTTS is to acquire general knowledge that is not specific or focused on specific learning.

In other words, the context of learning during a GTTS is not to guide and refine tourists towards higher-level thinking or improving their cognitive power but merely to inform and allow the tourists to know about a tourist destination. However, as in the context of classroom learning, the application of questions throughout a GTTS still drives the ability to think and offers a deep impact similar to that of the T\&L process [15]. Questions are important, especially, in encouraging classroom communication and to stimulate the minds of students to think [17], and this should also be the situation during a GTTS.

It is therefore important for a TG, who wishes to achieve their communication goals during a GTTS, to properly plan their questions so that they know the purposes and functions as well as the types or categories of questions that they intend to use. Moreover, according to Ong (2005) [18], most of the time, a TG only provides brief clarification and continuously offers further explanation from the beginning of the GTTS. It becomes a necessity for the TGs to play their roles as instructors not only by explaining but also incorporating other strategies to diversify the delivery pattern of information during the GTTS. 


\section{RESEARCH METHODOLOGY}

The sample for the research comprised five Malaysian, Japanese speaking TGs and a group of 17 Japanese tourists (JT) involved in five GTTS sessions. The TGs consisted of Malaysian citizens who had obtained a TG (JL) license from the Malaysian Tourism Ministry and they were labelled as TG1, TG2, TG3, TG4 and TG5 respectively. These TG's had all resided in Japan for at least one year and five months. In order to lead a GTTS, the TGs must have had at least one year of experience in working with GTTS at a minimum of one to four times per month. The JT subjects consisted of eight men and nine women who had never visited or participated in any GTTS previously. They were labelled JT1 to JT17 respectively.

Data collection was conducted around Melaka, one of Malaysia's popular tourism destinations via the FIT package. Melaka was chosen based on its widely-known historical and cultural foundations which influence the daily activities, religious beliefs and the surroundings of the local community. These factors appeared to raise the excitement and eagerness of the JTs to learn about the destination.

This study comprised qualitative research that used a systematic observation method. Audio and visual recordings were used to record the communication between the TGs and the JTs throughout the GTTS. This was to observe and record the behaviour of the subjects in a natural environment. This method recorded the selected events in a natural way, the events were then transcribed and coded into meaningful and explained units. The targeted data were the questions asked by the TGs to the JTs throughout the GTTS.

The five GTTSs were recorded over a duration of 22 hours and 55 minutes. The GTTS data via audio recordings were transcribed verbatim and the services of a JL expert were used to review the transcriptions so that they were in parallel and accurate with the recordings.

The data analysis was based on the categorisation of the questions asked by the TGs to the JTs. The TOEO in Cecil and Pfeifer (2011) [11] was used as the basis for summarising the functions of the questions regarding the explanations about the tourist destinations during the GTTS. This theory was used as the basis for the analysis because it consists of both of the domains that need to be present during GTTS interaction events. The theory was proven by Cecil and Pfeifer (2011) [11] who examined the level of questions during T\&L in the classroom. The content clearly outlined the category of thought in the sequence which covered all of the intellectual objectives of education [12].

\section{FINDINGS AND DISCUSSION}

The data analysis found that the application of the questioning strategy included seven categories of questions as in Figure 4. It was found that the percentage of questions to obtain consent was the largest category of question which comprised $42 \%$ of all question. This was followed by the category of question to obtain information which comprised $23 \%$ of the total questions. Each of the remaining question categories comprised less than $15 \%$ of the total questions respectively. Questions asking for an opinion as well as other question categories such as asking the JT to repeat the previous statement, or questions that were not aimed at obtaining information, and others comprised only $3 \%$ of the total questions respectively.

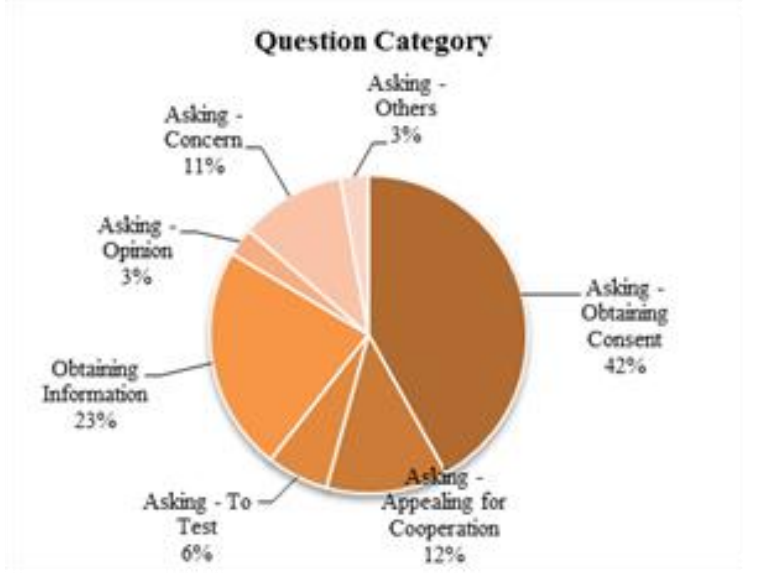

Figure 4 Application of Question Category

\section{a. Question Category - Asking for Consent}

Overall, the frequency of applying this category of question was $41.8 \%$ (205 frequencies) of the total questions applied by the TGs. Figure 5 shows that TG5 applied this category of question the most often, i.e. $32.2 \%$. While TG2 applied this category of question the least often $5.9 \%$.

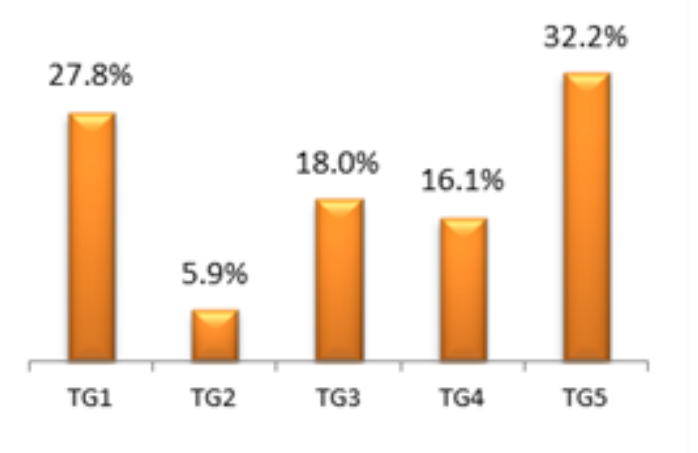

Figure 5 Question Category - Asking for Consent 
(1) - TG4: Sore wa purodua. Dakara, sore wa ne Miraa kee, Mira ppoi deshoo $\uparrow . /$ That (car) is Perodua. Since it has the shape of Mira, the car resembles Mira, right?

JT13: Ano maaku wa purodua $\uparrow /$ The logo is the Perodua's logo?

(2) - TG2: Asoko wa moo Marakka gawa desu ne. Ue kara mierun desu ne. De, asoko mo tatemono wo tsukuroo toshite tan desu. (JT6: Hai, hai) Demo ishiki mitsukatta kara, ima chuushi shiterun desu ne. Sugoin deshoo $\uparrow$ Kono hana wa, chotto kuruma ki wo tsukete ne. Kono miruto desu ne, are, yon, are, hidari, tora no monshoo are wa Mareeshia no seeshiki no monomonshoo desu./ Melaka river starts from there. Can be seen from above. And there is also a building site to be established (JT6: Yes, yes) but due to the discovery of the stone tree under it, the construction of the building has been stopped. Great isn't it? This flower, please be careful with the car. If we look at this, on the left is the tiger logo, the official logo of Malaysia.

JT6: Hai/YYes

Example (1) - TG4 posed a question to get consent from JT13 about the shape of a Malaysian car (Perodua) which resembles a Japanese-made car, namely the Mira is Perodua. Since it has the shape of Mira, the car resembles a Mira, right?]. JT13 provided feedback on TG4's questions by re-submitting the question to TG4 whereby JT13 indirectly agrees to the question.

Example (2) - TG2 posed a question asking for consent from JT6 about the fort located next to St. Paul's Hill. This form of question was asked after an explanation about the fort was given. Both of the questions are obtaining consent will end with the phrase "deshoo" at the end of the sentence to indicate that the speaker wants to get confirmation.

The application of this category of question functions by obtaining consent or opinion from the JT after the TG expressed his opinion at the end of an explanation of a given matter. The lexical "deshoo" at the end of the sentences, which was used in the application of this category of question, indicates that the TG was sensitive to the vocabulary, tone, and pronunciation differences when communicating with the JT. Overall, this category of question was aimed at strengthening the understanding of the JT after an explanation was offered. These questions were to ascertain whether the JT understood the explanation given. It was not set to test, analyse, categorise or apply other questions related to the cognitive domain. This category of question was within the context of Level I of Bloom's TOEO - affective domain. The questions were in the form of responding and the feedback that should be offered by the JT were; acquiescence in responding, willingness to respond and satisfaction in the response.

\section{b. Question Category - Obtaining Information}

Overall, the frequency of applying this category of question was at $23.0 \%$ (112 frequencies) of the total questions applied by the TGs. Figure 6 shows that TG1 applied this category of questions the most frequently, at a level of $30.4 \%$. While TG2 applied this category of questions the least, at a level of $4.5 \%$.

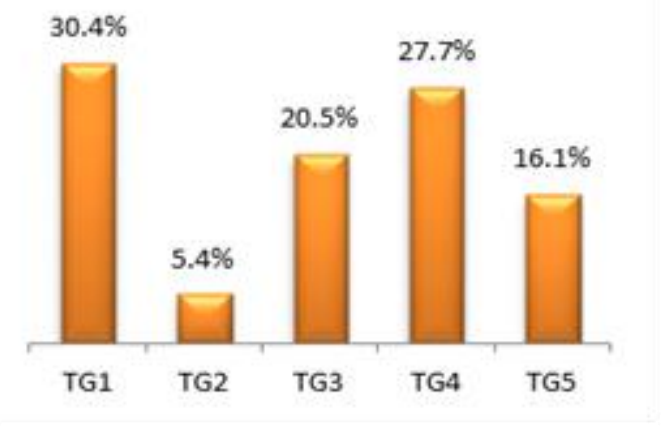

Figure 6 Question Category - Obtaining Information

(3) - TG2: Dakara bunka no sekaiisan de, ne, toroku saremashita. Sono tokoro mo ne, zutto kyoo ne, kengaku ni ikimasu. Marakka ikimashita ka $\uparrow /$ Thus (Malacca) is declared as a World Heritage Site. Throughout the day today, we will make a trip there. Have you ever been to Melaka? Eeto, itta koto nain desu. / Mm have not.

JT5:

(4) - TG3: Ja, nanigo shabetteru no $\uparrow /$ Well, what language is spoken?

JT10: Nanigo $\uparrow /$ What language?

TG3: Kotoba, eigo $\uparrow$ Ja, kondo, Yuri chan mo eigo umakunaru ne. English language? Soon, Yuri will be good in English.

JT10: Mada mada dayo ne demo, / Not yet, right. 
Example (3) - TG2 posed a closed-ended question to the JT5, whether they have been to Melaka or not. The question asked was aimed to obtain information for the purpose of the TG's self-reference so that actions taken along the GTTS were suitable. The feedback provided by JT5. If JT5 had never been to Melaka before, then a more detailed description and explanation of the tourist destinations in Melaka should be provided.

Example (4) - TG3 posed an open question to JT10 about what language is used in school JT10. The question was aimed at obtaining information for the purpose of communicating, with the intention to establish and to maintain a good relationship between TG3 and JT10 during the GTTS.

The application of this category of question was aimed at obtaining information from the JT to enable the TG to take appropriate steps or actions to facilitate smooth communication and operations throughout the GTTS. As this category of questions are designed to obtain consent as described earlier, and furthermore, as explained, this category of questions are not meant to test, analyse, categorise or apply other questions to test one's thinking. It is in the context of Bloom's Level I TOEO - affective domain. This category does not apply the minds of JTs but is merely to obtain information. What is needed or expected is only acquiescence in responding, a willingness to respond and satisfaction in the response, as in the context of Bloom's Level I TOEO - affective domain.

\section{c. Question Category - Appealing for Cooperation}

Overall, the frequency of applying this category of question was at $12.0 \%$ (61 frequencies) of all of the questions asked by the TGs. Figure 7 shows that TG1 applied this category the most often, at a level of $98.4 \%$ and TG5 applied the question category the least, at a level of $1.6 \%$. While the other TGs did not apply this category at all. TG1 tended to use this category due to their lexical shortage in L2 (second language) while communicating during the GTTS.

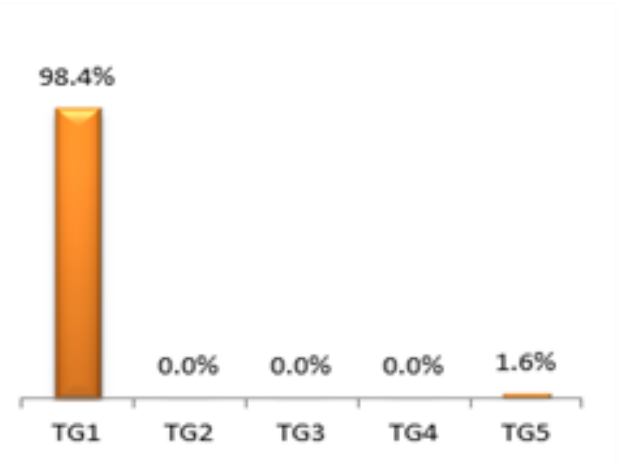

Figure 7 Question Category - Appealing for Cooperation

(5) - TG1: Picnic, Err, Eigo de nan desu ka. Eego wa Barbeque, Nihongo de nan desu ka. (JT1: N个) A, barbeque, barbeque wa grill/ Picnic, Err, what it is called in English? In English it is called barbeque, what is called in the Japanese language? (JT1: $\uparrow \uparrow$ ) Yes, Barbeque, Barbeque is roasting.

JT1: Baabekyuи, baabekyuи, anoo nihongo deo baabekyuи to iimasu. / Barbeque, Barbeque, in Japanese it is called Barbeque.

TG1: A, soo $\{$ Warau $\} /$ Oh really? $\{$ Laugh $\}$

(6) - TG1: Eeto, Ermm Mareeshia no shoohin no rekishi no naka de marakka wa seekaijuu kara a, a, How to say desu Trader.Trader wa toreedasu, Ermm, Erm toreedasu, ett, booeki no aa kata ne./ Ermm in the history of Malaysian goods, Melaka was the place where all the world's goods are gathered. How to say? Traders, traders are Toreedasu. Mmm Toreedasu, people who involved in trading right?

JT1: $\quad A, a /$ Yes, yes

Example (5) - TG1 asked the question to JT1 as a strategy of appealing for cooperation from JT1 to get the word "Barbeque" in the JL. In addition, to give a clearer picture to JT1 so that the exact word was attained, TG1 clarified the meaning of the word in detail.

Example (6) - TG1 posed a question to JT1 - How to say? In the mode of code transfer as a strategy for appealing for cooperation from JT1 for the purpose of obtaining the word besides explaining the meaning of the word "Trader" in detail. TG1 also made an attempt to reveal the word in the JL - "Toreedasu" however, the exact pronunciation is "Toreedaa".

The data analysis found that the communication was interrupted in the form of speech which exhibited where
TG1 encountered linguistic problems to deliver his message while communicating. To ensure continuous communication, and that messages were delivered, TG1 clearly applied an appeal for co-operation through the questions directed to the JTs. In fact, this category of question helps to bridge the gap that exists in the cultural communication between two parties.

TG1 dominated this category of questions at a level of $98.4 \%$ compared to the other TGs. When looking into the definition of the strategy of appealing for cooperation, it is generally applied when a speaker asks for assistance from the listener to get the correct form or the correct lexical/word. However, this application should not be considered negative as a positive effort was made by TG1 
to immediately participate in a communication event when there was a gap as a result of his weakness in the JL. The data also found that there was no cultural or ethical difference in applying this category of question.

From the perspective of data analysis, this category of question may not be present during other communication events because the communication in this study involved a third language, namely the JL, which fostered the use of several strategies in order to smooth communications during the GTTS process. Applying this category of question was not to test, analyse or for any other purposes. Basically, it was just a communication strategy used by the TG which was in line with Level I of Bloom's TOEO affective domain. What was needed or expected was tranquillity in the response that consisted of acquiescence in responding, a willingness to respond and a satisfaction in the response.

\section{d. Question Category - Showing Concern}

Overall, the frequency of the application of this question category was at $10.8 \%$ (53 frequencies) applied by the TGs from the overall number of questions. Figure 8 shows that TG3 applied this strategy the most often at a level of $47.2 \%$. While TG5 applied this strategy the least, at a level of $3.8 \%$.

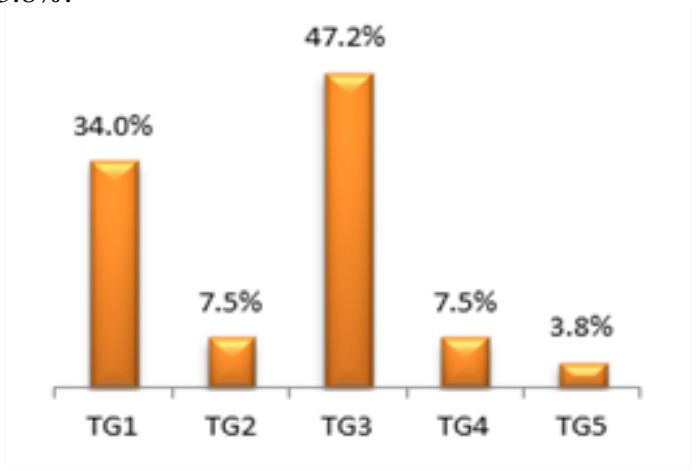

Figure 8 Category of Question - Concern

TG1: OK, kochira he doozo, saigo, saigo / Hai, kochira he saigo desu, (Mareego) Hai, kochira kara (JT1 : Hai) Kochira shashin torimashoo ka $\uparrow /$ Okay, please go to the last (destination) here. (Malay) Good from now（JT1: Yes） Take a picture here first?

\section{(8) - $\quad$ TG3: Kore kara ichi ji kan gurai arukiamsu ga, daijoobu desu ka $\uparrow$ /From now onwards, we will need to walk for an hour, are you okay? \\ JT10: Daijoobu desu./Yes, I am okay.}

Example (7) - TG1 posed a question to offer or provide suggestions to the JTs in taking pictures at a suitable place before heading to the last tourism destination of the GTTS. The questions raised were based on TG1's concern of the behaviour of the JTs who were known to be fond of taking photos during GTTS. The question was asked to ensure that the JTs under the control of the TG did not miss the opportunity to take pictures as they were at the end of the GTTS, TG1 recommended that they take pictures at the venue.

Example (8) - TG3 informed JT10, that they will need to walk to of St. Paul's hill. The TG posed questions based on TG3's concern over the situation of JT10 who was walking whilst carrying her baby girl (JT12) to climb up St. Paul's hill. The questions asked were based on TG3's concerns over the possible problems that might be faced by JT10 if the GTTS continued by climbing up St. Paul's hill.

The application of this category of question worked to express the TG's concern over the JT and this type of action may eventually be able to create a harmonious relationship between them. Such a harmonious relationship may exist due to the concerned attitude of the TG towards the needs of the JTs which makes them feel safe, comfortable and able to enjoy the GTTS. It was observed from data analysis that the application of this type of question was only to enhance the comfort of the
JTs and was not to test, analyse, categorise or intended to test their thinking.

The questions were only to show concerned for the JTs, and to obtain information from the JTs to enable the TG to take appropriate action to ensure smooth communication and operations throughout the GTTS. This category of question is at Level I of Bloom's TOEO - affective domain. On the other hand, this category of question does not imply that the JTs must think, but is only to get information. What is needed or expected is only response in the form of acquiescence in responding, a willingness to respond and a satisfaction in the respon

\section{e. Question Category - Testing}

Overall, the frequency of applying this category of question was at a level of $6.0 \%$ (22 frequencies) applied by the TGs from the overall number of questions. Figure 9 shows that TG2 applied this category the most frequently, which was at a level of $54.5 \%$. While TG4 applied this category the least often, which was at a level of $4.5 \%$. 
(9) -

JT14: Kuni no hana ka, National flower./State flower is it, national flower?

TG4: Soo. Shingapooru no hana wa, shitte masu $\uparrow /$ Yes. Do you know Singaporean state flower?

JT15: Shingapooru no hana wa, ran desu./ National flower of Singapore is Orchid.

TG4: Soo, ran desu. Nihon no hana wa $\uparrow$ / Yes, Orchid. Japanese national flower?

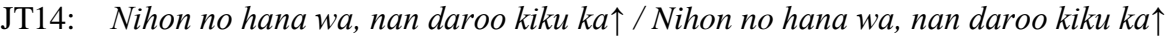

TG4: Kiku ka, sakura to chuu ne / Chrysanthemum is it, Sakura Kiku ka

$(10)-$

TG2: Ne, de, e, koocha wa mukashi wa Ceylon kara motte kimashita / Tea, are brought from Ceylon

JT5\&JT6: $\quad$ Aa, hai, hai / Yes, yes

TG2: Ceylon ima wa nanno, nanno namae desu ka, atarashii namae $\uparrow /$ What is Ceylon now, what is the name? New name?

JT6: Ceylon no, Ceylon no xxxx ka na $\uparrow /$ What is Ceylon, Ceylon's xxx is it?

TG2: Ceylon wa furui namae ne, / Ceylon is the old name, right?

JT6: Furui $\uparrow /$ Old?

TG2: Atarashii namae / New name?

JT6: Sri Lanka / Sri Lanka

TG2: Pinpon Sri Lanka desu./Yes correct, Sri Lanka

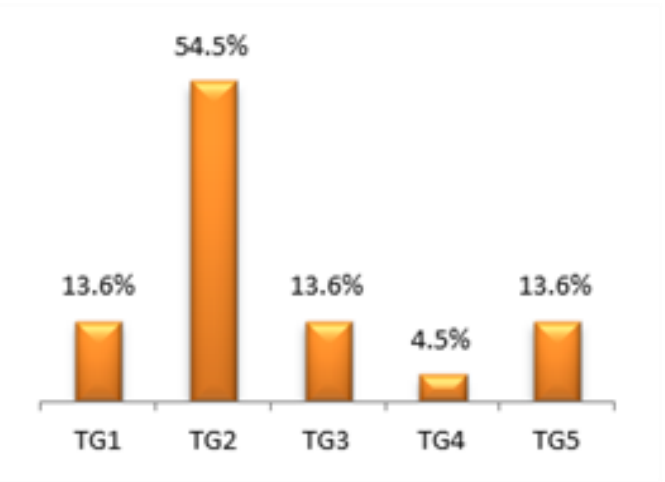

Figure 9 Category of Question -Testing

Example (9) - TG4 tested both JT14 and JT15 by asking questions about the national flower of Japan. This category of question was an effort by TG4 to stimulate and push the thinking of the JTs by starting to test the JT's knowledge of Singapore's national flower. This question tried to encourage the JTs to think about finding the answer and indirectly made the JTs focus on the tour's information.

Example (10) - TG2 tested both JT5 and JT6 by asking questions about the new name for Ceylon. The question raised some excitement for JT5 and JT6 who both wished to provide the correct answer. This situation stimulated the thinking of the JTs and indirectly made the JTs focus more on the tour's information.

The application of this category of question was not intended to obtain information but only to diversify the method of presentation during the GTTS so that the JTs were focused during the explanation given during the GTTS. Indirectly this category of question also stimulated and encouraged the thinking of the JTs to provide feedback or to know more about the topics raised by the
TGs. The application of this category of question was something that was natural and prevalent during the GTTS and was easy for the TGs to use due to their wide-ranging knowledge of Japan. In fact, the application of this question was an effort by the TGs, as the GTTS leaders, to ask questions as a medium to increase anticipation, stimulate curiosity, seek different views and to provoke and stimulate new ideas in the JT's throughout the GTTS. In contrast to the other categories of question, this category of question is more towards the cognitive testing parallel of Level I of Bloom's TOEO - cognitive domain.

\section{f. Question Category - Asking for Opinion}

Overall, the frequency of applying this category of question was at a level of $2.9 \%$ (14 frequencies), applied by the TGs from the overall number of questions. Figure 10 shows that TG3 applied this category the most often which was at the $50.0 \%$ level. While TG1, TG2 and TG5 applied these questions the least, which was at a level of $7.1 \%$ each

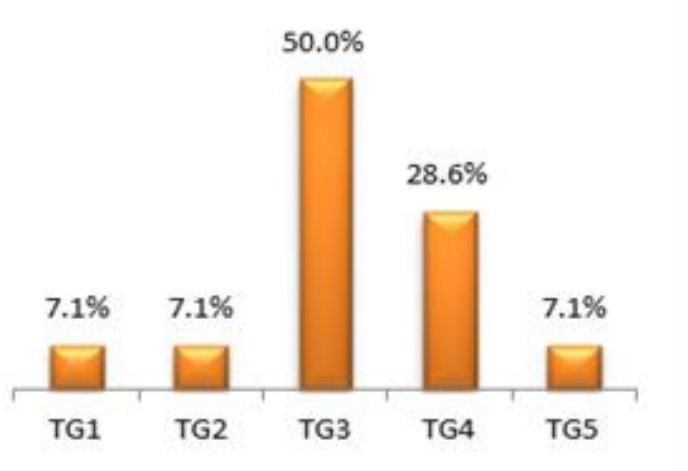

Figure 10 Questions Category - Asking for Opinion 
(11) - JT10: Kore hitotsu to kore, / This one, one and this, one.

TG3: Kore wa doo $\uparrow /$ How about this one?

JT10: Nani wa hatte run desu ka, tabeta koto nai desu kedo, / What is the filling inside? I have never tasted it before.

TG3: Kore hitotsu, hitotsu / This, one.

(12) Daijoobu datta, sugoi ne, ee, Dooshimasu ka $\uparrow$ Chuushoku he ikimasu ka. Ja chuushoku no tokoro he ikimasu ne. Hai, kore de chotto sutoppu shimasu. Ja, mata aimasho. Arigatoo gozaimasu./ Are you okay? Good. How ya? Go to lunch? Let's go for lunch. Alright, we stop here first (recording) for a while. See you again. Thank you.

Example (11) - TG3 asked a question to obtain JT10's opinion about ordering food during the tea break. The question was aimed at obtaining JT10's opinion, suggesting that JT10 should decide on the proposed food selection. In this situation, as observed, TG3 not only obtained JT10's opinion regarding the food but in addition made a decision on behalf of JT10 to choose the food with JT10's consent by ordering a pie with the cafeteria waiter. Example (12) - TG2 posed a question by asking JT5's opinion, under his supervision, whether to proceed with the GTTS to the next destination or to stop for lunch. The question was aimed at obtaining JT5's opinion to make a choice, with reference to TG2's question, so that an action would be taken, which would be agreed by the JTs under his control. However, the situation was observed as TG2 not only obtaining the opinions of the JTs under his control to continue the visit or stop for lunch, but also in making a decision with the indirect consent on behalf of the JTs to stop for lunch.

The application of this category of question was not only aimed at obtaining the JT's thoughts but also to include the JTs in the decision making related to the GTTS. In fact, some of these categories of questions are plausible even though initially it is in the form of questions asking for opinions from the JTs. Next was added the aspect that the question was a learning process for the GTTS which is business service oriented. Therefore, to ensure the comfort, safety, needs and desires of the JTs throughout the GTTS, the TGs should take into account the opinions of the JTs. The application of this category of question was not intended to test, analyse or for other reasons. It was just a communication strategy used by the TG which was in line with Level I of Bloom's TOEO - affective domain.
Therefore, the expected response was an acquiescence in responding, a willingness to respond and a satisfaction in the response to the question raised.

\section{g. Question Category - Other Purposes}

Overall, the frequency of applying this category of question was at 3\% (14 frequencies), as applied by the TGs from the total number of questions. These questions were categorised as 'other purposes' because the identified categories of questions constituted less than $5 \%$ of the total number of questions. Among them were initiating of conversations, submitting or highlighting issues in the form of explanation, requesting a question to be repeated in asking for permission and questions that were not designed to attain feedback/response. Figure 11 shows that TG5 applied this question category the most frequently which was at $42.9 \%$. Furthermore, TG3 did not directly apply any questions from this category.

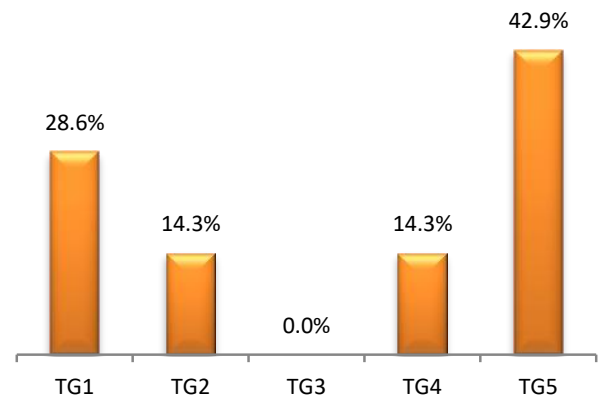

Figure 11 Question Category - Other Purposes

(13)- TG1: Aa OK. How much the cost $\uparrow$ Like that this ne (JT1: Nn). This is sitting (JT1: Aa) This is the how to say KL to Singapore train. 68 (JT1: Ringi $\uparrow)$ So yasui deshoo $\uparrow(J T 1:$ Yasu)/ AaOK. How much the cost $\uparrow$ Like that this ne (JT1: Nn). This is sitting (JT1: Yes) This is the how to say KL to Singapore train. 68 (JT1: Ringit $\uparrow$ ) That is cheap right $\uparrow$ (JT1: Yes it's cheap)

JT1: Ett Singapore to KL ni 68 ringi $<T G 1$ : Soo $>\uparrow /$ Singapore to KL is about 68 ringit $<T G 1$ : Yes $>\uparrow$ ne $\uparrow$ (JT6: Nn). Mada nazonazo nan desu ne (JT5: N), de, kore zenbu ohaka no ishi. Mareeshia wa kyoo mo Isuramu kyoo to Kirisuto kyoo to Bukkyoo wa doosoo ni narimasu. (JT6: N, n) Bukkyoo to Hinzuи kyoo wa kasoo desu. Still a question mark. Therefore, perhaps a missionary 
from Japan has visited here (JT6: Nn) Still a mystery. It's also an eetle (JT5: Ee) yes, right (JT6: Dayan (Who is in Osaka's accent) Who is it? $\uparrow$ (JT6: Yes.) Still a question mark (JT5: N) and these are tombstones. Malaysia today also equally has religion of Islam, Christianity and Buddhism. (JT6: N, n) Buddhism and Hinduism are the underlying religion.

JT6: $N, n$

Example (13) - TG1 posed a question that was not directly to JT1 but as a benchmark or to highlight a topic in a conversation. The questions that were being asked did not require the JT to answer but they symbolised the beginning of a conversation regarding a topic.

Example (14) - TG2 posed a question that was not addressed to JT6, who was under his control, the question was designed to present or highlight an issue about his explanation about a tombstone, an historical artifact found at St. Paul's Church related to the arrival of a Japanese missionary to the church. The question asked did not require the JT to answer the question raised but was simply used to lure the JT's attention to his explanation. JT6 only provided feedback on the issue $-N, \boldsymbol{n} /$ Yes.

The categories of these questions were not categorised in detail as they comprised only $3 \%$ of the total questions. They were not designed to test, analyse, categorise or be applied in other ways and were related to the cognitive domain. These questions were within the context of Level I of Bloom's TOEO - affective domain. The JTs only needed to be concerned about the environment, but some of them did not give specific answers to those questions. Both Figures 11 and 12 denote the conclusions of the application of the categories of questions by the TGs according to the seven categories of questions and the question levels based on the TOEO, Bloom (1984) [1] in Cecil and Pfeifer (2011) [11]. Figure 12 is the frequency distribution of each category of question by the TGs. It clearly indicates that the distribution of the application of the questions was uneven. Especially in the category of questions appealing for cooperation. TG1 dominated this category compared to the other TGs. If we look in depth at the definition of the strategy of appealing for cooperation, the strategy is applied when a speaker is seeking help from the listener to get the right form and lexical or the correct word. This category of question was applied by those who had only acquired low levels of language mastery. Furthermore, this explanation coincides with the Communication Strategy by Tarone (1977) [19]. The strategy is known as the Appeal Strategy which is interpreted as a strategy used to help launch communication as a result of low levels of language mastery.

This proves that the level of mastery of the JL by TG1 was weak compared to the other TGs. This category of question was relevant at the model level that will be developed in the context of the GTTS as it did not exist for the other TGs.

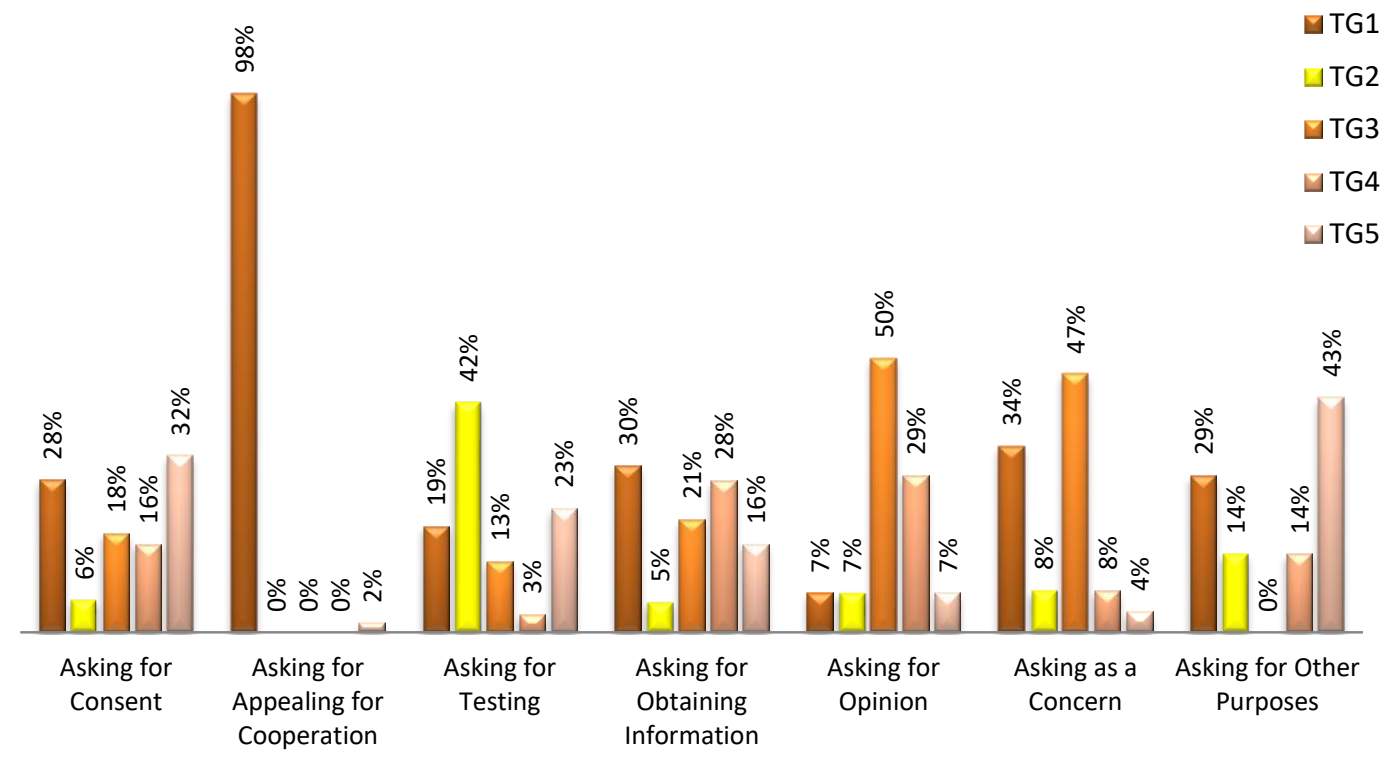

Figure 12 Categorization of Questions according to the question Category

Therefore, only six categories of questions were coordinated at each level and domain in the Model of Question Level in the GTTS as shown in Figure 13. The figure shows that the categories of the questions used during the GTTS were divided into two domains namely the affective domain and the cognitive domain. Since the GTTS was not designed to motivate or improve the thinking of the GTTS participants as in a T\&L 
environment, the data analysis identified that five categories of questions were comprised of affective domains. However, even though the GTTS was not an activity that was thinking-oriented, the cognitive domain remained as it was still related to learning. However, this category of questions only consistsed of one category. On the other hand, the application of the category of questions for both domains was within Level I in the two domains of the TOEO, Bloom (1984) [1].

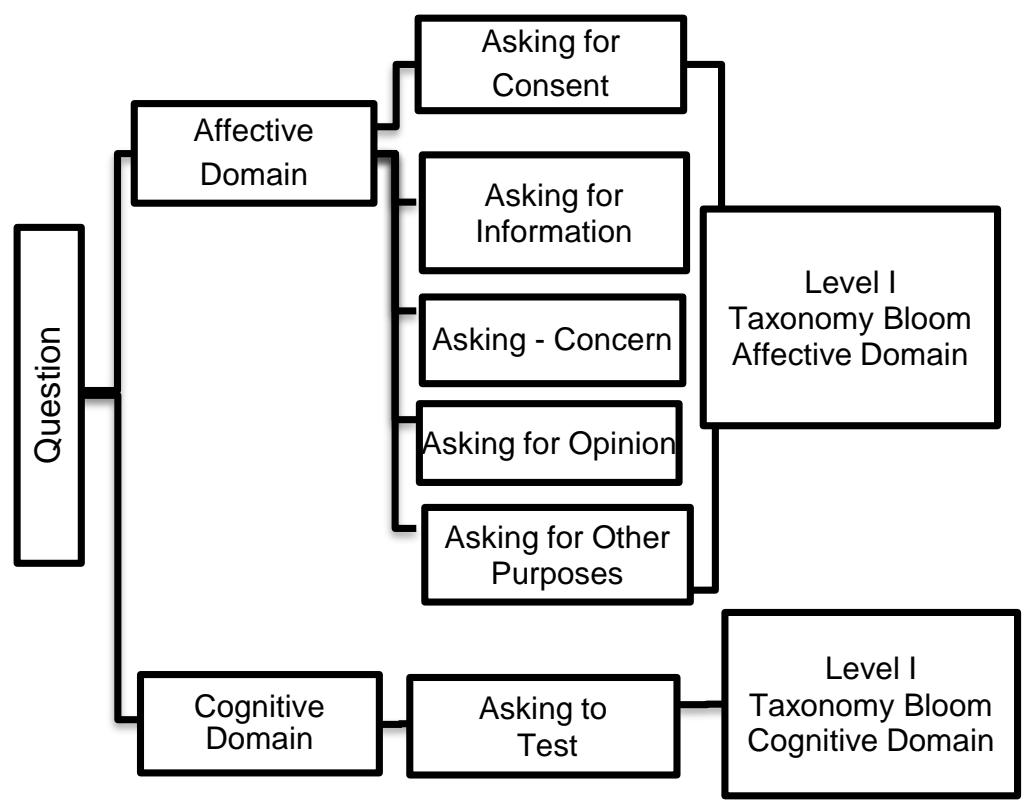

Figure 13 Model of Question Level in the GTTS

The model developed above summarises the differences in the level and the category of questions applied during the GTTS compared to the levels and categories of question contained in the T\&L environment. The findings of the study summarised that the TGs often used questioning strategies, applied questioning skills, various categories of questions and contexts which were appropriate when asking questions. However, there was also the use of aspects of questioning skills, question categories and the context of questionable and lesser questions which should be emphasised by the TGs. This study provided exposure to the questions that TGs should use during the handling of a GTTS because by asking appropriate questions, such questions will further enhance the effectiveness of the TG's communication with the JTs.

\section{CONCLUSION}

The findings of the study not only indicated that questioning was an important process during GTTS communication by the TGs but also explained how the TGs used the categories of questions, at suitable levels that corresponded to the GTTS context. In addition, the findings indicated that there wasn't any use of categories of questions or levels of applying questions that may have contradicted with the JT's culture or caused a conflict. Furthermore, the findings of the study have shown the implications of some aspects of questioning activities that ensured the smoothness of communication during the GTTS.
The suggestions from this study are presented in the form of a model of the levels of question that should be applied by TGs. This model should be circulated, to increase the empowerment of JL teaching and also to act as a guide for TGs when preparing to explain to JTs about destinations visited during GTTS in Malaysia.

Overall, these findings provide guidance in the application of questions for the purpose of smooth communication during GTTS. This study has exposed the questioning activities that should be used by TGs when conducting GTTS because the appropriate application of questions will improve the effectiveness of TG's communication with JTs.

\section{ACKNOWLEDGMENT}

Thank you to the Malaysia Ministry of Education (MOE) and University Malaysia Terengganu (UMT) for the financial supports through FRGS (Ref.Code: FRGS/1/2018/SSI01/UMT/03/2).

\section{REFERENCES}

[1] B. S. Bloom, The two-sigma problem: The search for methods of group instruction as effective as one-toone tutoring. Educational Researcher, 13(6) (1984) 4 16. 
[2] Y. Aydemir and Y, \& O. Çiftçi Ö, Literature Teachers' Questioning Skills: A Study on Faculty of Education of Gazi University Case. 2008. Centenary University J. Faculty Educ., 6(2), 103-115.

[3] C. Tyers, An examination of the interrogative clause and the associated problems for a group of Japanese learners of English at a junior college in Japan. Kagoshima Junshin Joshitanki Daigaku Kenkyuu Kiyoo, 30 (2000) 163-180. DOI: http://www.kjunshin.ac.jp/juntan/libhome/bulletin/No30/print/Tyers. pdf

[4] A. Krismanto, Beberapa teknik, model, dan strategi dalam pembelajaran matematika. Yogyakarta: Depdiknas Dirjen Pendidikan Dasar dan Menengah. 2003.

[5] R. T. Cunningham, What kind of question is that? In W. W. Wilen (Ed.), Questions, questioning techniques, and effective teaching. Washington, DC: National Education Association of the United States. (1987) 6794.

[6] Idris, N. (2005). Pedagogi dalam pendidikan matematik. Utusan Publications.

N. Idris, Pedagogi dalam pendidikan matematik. Utusan Publications. 2005.

[7] Z. Mahamod \& N. R. Lim, Kepelbagaian kaedah penyoalan lisan dalam pengajaran guru bahasa melayu: kaedah pemerhatian. 2011. Jurnal Pendidikan Bahasa Melayu.1(1), 51-65. http://journalarticle.ukm.my/2540/.

[8] R. Kubota, Japanese Culture Constructed by Discourse: Implications for Applied Linguistics Research and ELT. Teachers of English to Speakers of Other Languages, Inc. (TESOL) Japanese, 102(4) (1999) 9-28. http://doi.org/10.1093/jnci/djq062

[9] C. Devereux, More than 'Have a Nice Day': Cross cultural service competence and the tourist industry. Developments in the European Tourism Curriculum. The Netherlands: ATLAS, Tilburg University. 1998.

[10] H. Rubin, Collaborative leadership: Developing effective partnerships for communities and schools. Corwin Press. 2009.

[11] N. L. Cecil and J. Pfeifer, The art of inquiry: Questioning strategies for K-6 classrooms. Portage \& Main Press. 2011 DOI: https://www.amazon.com/ArtInquiry-Questioning-Strategies-

Classrooms/dp/1553792548

[12] N. R. Mansor, Aras kognitif soalan. Kuala Terengganu: Penerbit Universiti Malaysia Terengganu. 2007.
[13] B. S. Bloom, Taxonomy of Educational Objectives: Cognitive Domain. New York: David McKay Company. 1956.

[14] N. M. Sanders, Classroom questions: What kinds?. Harpercollins College Div. 1966.

[15] G. Muthy, Aras penyoalan dan pemikiran dalam proses pembelajaran bahasa melayu murid sekolah rendah (Doctoral dissertation, Fakulti Bahasa dan Linguistik, Universiti Malaya). 2013.

[16] D. A. Smith, D, Levels of questioning: Teaching creative thinking through ESP. English Teaching Forum, January(12) (1981) 15-17.

[17] E. C. Wragg and G. A. Brown, Questioning in the primary school. Routledge. 2002. DOI: https://content.taylorfrancis.com/books/download?dac= C2010-0-37563-

$6 \&$ isbn=9781134534708\&format=previewPdf

[18] L. T. Ong, Analisis lakuan komunikatif pemandu pelancong semasa bertugas. Dewan Bahasa Dan Pustaka, 5(4) (2005).

[19] E. Tarone, Conscious communication strategies in interlanguage: A progress report. on TESOL, 77 (1977) 194-203. 